\title{
Quantitative angiography after directional coronary atherectomy
} P W Serruys, V A W M Umans, B H Strauss, R J van Suylen, M van den Brand,
H Suryapranata, P J de Feyter, J Roelandt

\section{Abstract}

Objective-To assess by quantitative analysis the immediate angiographic results of directional coronary atherectomy. To compare the effects of successful atherectomy with those of successful balloon dilatation in a series of patients with matched lesions.

Design-Case series.

Setting-Tertiary referral centre.

Patients- 62 patients in whom directional coronary atherectomy was attempted between 7 September 1989 and 31 December 1990.

Interventions-Directional coronary atherectomy.

Main outcome measures-Increase in minimal luminal diameter of coronary artery segment.

Results-Angiographic success on the basis of intention to treat was obtained in 54 patients $(87 \%)$. In four patients the lesion could not be crossed by the atherectomy device; all four had an uneventful conventional balloon angioplasty. Four of the 58 patients who underwent atherectomy were subsequently referred for coronary bypass surgery because of failure or complications; three of them sustained a transmural infarction. In the successful cases, coronary atherectomy resulted in an increase in the minimal luminal diameter from $1.1 \mathrm{~mm}$ to $2.5 \mathrm{~mm}$ with a concomitant decrease of the diameter stenosis from $62 \%$ to $22 \%$. In the subset of 37 patients in which the changes induced were compared with conventional balloon angioplasty atherectomy increased the minimal luminal diameter more than balloon angioplasty (1.6 $v 0.8 \mathrm{~mm} ; \mathbf{p}<0.0001)$. Conventional histology showed media or adventitia in $26 \%$ of the atherectomy specimens. In hospital complications occurred in six patients who had undergone a successful procedure: two transmural infarctions, two subendocardial infarctions, one transient ischaemia attack, and one death due to delayed rupture of the atherectomised vessel. All patients were clinically evaluated at one and six months. One patient had persisting angina (New York Heart Association class II), one patient sustained a myocardial infarction, one patient underwent a percutaneous transluminal coronary angioplasty for early restenosis, and one patient underwent coronary bypass surgery because of a coronary aneurysm formation. At six months $80 \%(36 / 47)$ of the patients were symptom free.

Conclusions-Coronary atherectomy achieved a better immediate angiographic result than balloon angioplasty; however, in view of the complication rate in this preliminary series, which may be related to a learning curve, a randomised study is needed to show whether this procedure is as safe as a conventional balloon angioplasty.

Percutaneous transluminal coronary angioplasty was reported in 1978 by Gruentzig ${ }^{1}$ as a non-operative technique for the treatment of single, discrete, and proximal coronary artery stenosis in patients with symptomatic ischaemic heart disease. Over the past decade improved technology and operator experience have led to a greater use of conventional coronary angioplasty with an excellent immediate success rate. ${ }^{23}$ As indications for coronary angioplasty expanded and more difficult lesions were attempted, the likelihood of acute complications increased. The most dangerous complication is acute occlusion which is encountered in $2-10 \%$ and frequently requires emergency surgical revascularisation. ${ }^{45}$ Although acute occlusion is occasionally caused by thrombosis, it is usually caused by an intimal dissection. ${ }^{67}$ In particular lesions with a complex shape have a greater tendency to occlude abruptly. ${ }^{4}$ The use of new techniques might reduce acute complications after conventional balloon dilatation. ${ }^{8-11}$ Although balloon angioplasty can efficiently dilate a stenosis, recoil is one of the immediate mechanisms that results in the loss of $50 \%$ of the balloon angioplasty result. ${ }^{12}$ Several newly developed techniques have been designed to debulk coronary tissue thereby reducing the potential effect of elastic recoil.

Atherectomy is one such technique that might lead to fewer acute complications and less recoil because the plaque is removed rather than merely disrupted by the balloon inflation. There are published reports on the safety and short term results of atherectomy. ${ }^{13-16}$

We have assessed the immediate clinical and angiographic results of coronary atherectomy using quantitative coronary analysis as an objective method. 
Table 1 Clinical and angiographic characteristics in 58 patients who had atherectomy

\begin{tabular}{|c|c|}
\hline Characteristic & No \\
\hline \multicolumn{2}{|l|}{ Sex: } \\
\hline Male & 49 \\
\hline Female & 9 \\
\hline Age (yr) mean (SD) & 58 \\
\hline \multicolumn{2}{|l|}{ Infarction: } \\
\hline Old & 14 \\
\hline Recent & 9 \\
\hline \multicolumn{2}{|l|}{ NYHA: } \\
\hline II & 18 \\
\hline III & 17 \\
\hline IV & 23 \\
\hline \multicolumn{2}{|l|}{ Stenosis: } \\
\hline Primary & 39 \\
\hline Restenosis & 19 \\
\hline \multicolumn{2}{|l|}{ Anatomy:^ } \\
\hline $\mathrm{LAD}$ & 37 \\
\hline $\mathrm{LCx}$ & 9 \\
\hline RCA & 15 \\
\hline Graft & 3 \\
\hline
\end{tabular}

*Four patients underwent two procedures, and one patient had three procedures.

NYHA, New York Heart Association; LAD, left anterio descending; LCx, circumflex artery; RCA, right coronary artery.

\section{Patients and methods \\ PATIENTS}

From 7 September 1989 to 31 December 1990 62 patients underwent attempted directional coronary atherectomy at the Thoraxcenter. Four patients underwent two atherectomy procedures and one patient had three procedures. In four patients atherectomy was attempted but the stenosis could not be crossed by the device and all were subsequently treated by balloon angioplasty. All procedures were performed in patients with angina refractory to anti-ischaemic treatment. The study group (table 1) consisted of 49 men and nine women (mean (SD) age 58 (10)). A previous myocardial infarction was documented in 23 patients and nine of these patients were treated because of postinfarction angina. Four patients had prior surgical bypass grafting and 19 patients underwent atherectomy as a second percutaneous revascularisation procedure after previous conventional angioplasty $(n=12)$, after previous stenting $(n=5)$, or after previous atherectomy $(n=2)$. Two patients had a cardiac transplantation and another patient had had a kidney transplant. At the same time of atherectomy 23 patients were in New York Heart Association functional class IV, 17 in class III, and 18 in class II. Coronary angiography showed one vessel disease in 47 patients, two vessel disease in seven, and three vessel disease in four. The obstruction was in the left anterior descending artery in 37 procedures, in the right coronary artery in 15 , in the circumflex artery in nine, and in the venous bypass graft in three cases.
Fifty two patients were selected for an elective atherectomy procedure and in six patients atherectomy was performed as an adjunct and bail-out procedure to a conventional balloon dilatation to prevent emergency coronary bypass surgery for the following reasons: obstructive dissection $(n=4)$, primary total occlusion $(n=1)$, and reocclusion after balloon angioplasty $(n=1)$. Three atherectomy procedures were performed in patients who required prophylactic haemodynamic support by means of intra-aortic counterpulsation $(\mathrm{n}=1)$ or by percutaneous cardiopulmonary support $(\mathrm{n}=2)$.

PROCEDURE

After administration of local anaesthesia a 11 French sheath was inserted into the femoral artery. All patients were given $250 \mathrm{mg}$ aspirin and $10000 \mathrm{U}$ heparin intravenously. Then a 7 French guiding catheter was placed in the ostium of the coronary artery for initial angiograms in multiple views. This was replaced by the special 11 French guiding catheter. Then the atherectomy device (fig 1) was advanced by the over the wire technique and positioned across the stenosis. After proper positioning the support balloon was inflated up to 0.5 atmospheres, the cutter was retracted into the housing, and balloon inflation pressure was increased to 2 to 3 atmospheres. The driving motor was activated and the rotating cutter was slowly advanced to cut and collect the protruding intimal lesion in the collecting chamber located at the tip of the catheter. After each pass (mean (SD) $6 \cdot 1$ (2.9) ) the balloon was deflated and either removed or repositioned. Atherectomy was regarded as successful when the residual stenosis was less than $50 \%$ of the vessel diameter and plaque material was present in the collecting chamber. After atherectomy the arterial and venous sheaths were usually left in place for six hours. Patients were monitored for 24 hours; electrocardiograms were obtained twice a day and cardiac enzyme concentrations measured twice a day. Nifedipine was given every two hours for 24 hours after the procedure and aspirin was given for one year. All atherectomy procedures were performed after the patient had given informed consent.

\section{QUANTITATIVE CORONARY ANGIOGRAPHY}

Quantitative analysis of the coronary segments was performed with the computer based Coronary Angiography Analysis System (CAAS), described in detail elsewhere. ${ }^{1718}$ In essence, the boundaries of a selected coronary artery segment were detected automatically
Figure 1 Simpson's directional AtheroCath

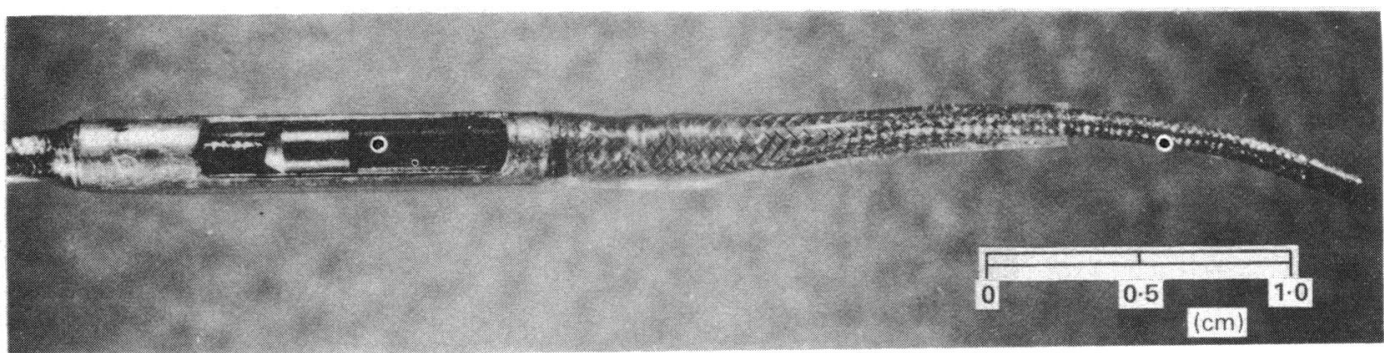


from optically magnified and video digitised regions of interest $(512 \times 512$ pixels $)$ of a cineframe. The absolute diameter of the stenosis in $\mathrm{mm}$ was determined with the guiding catheter as a scaling device. Calibration of the catheter as an absolute value $(\mathrm{mm})$ was achieved by comparing the mean diameter of the guiding catheter in pixels with the measured size in millimetres. Each catheter was measured individually. To correct the detected contour of the arterial and catheter segments for pincushion distortion, a correction vector was computed for each pixel based on a computer-processed cineframe with a centimetre grid placed against the input screen of the image intensifier. Because the functional significance of a stenosis is related to the expected normal cross sectional area of a vessel at the point of obstruction, we used a computer estimation of the original dimension of the artery at the site of the obstruction to define the interpolated reference area. The percentage diameter and area stenosis and the minimal luminal diameter $(\mathrm{mm})$ and cross sectional area $\left(\mathrm{mm}^{2}\right)$ were then calculated. The length of the lesion $(\mathrm{mm})$ was determined from the diameter function on the basis of a curvature analysis. In addition, this technique allowed the assessment of the eccentricity of the lesion for a given view. The symmetry index ranged from 0 (totally eccentric stenosis) to 1 (symmetric). The degree of coronary bend was assessed by the curvature value at the obstruction site. This variable was computed as the average value of
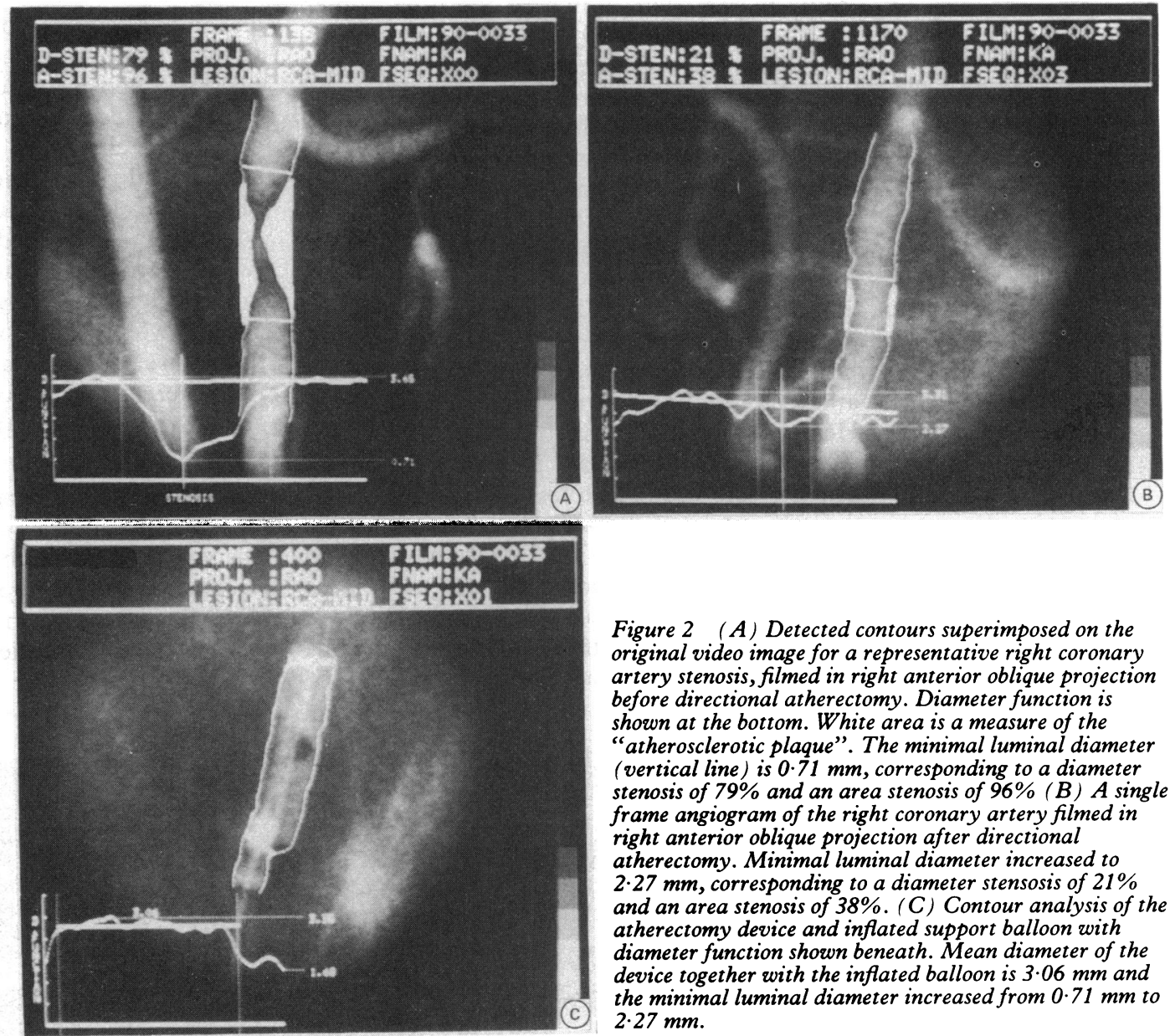

Figure 2 (A) Detected contours superimposed on the original video image for a representative right coronary artery stenosis, filmed in right anterior oblique projection before directional atherectomy. Diameter function is shown at the bottom. White area is a measure of the "atherosclerotic plaque". The minimal luminal diameter (vertical line) is $0.71 \mathrm{~mm}$, corresponding to a diameter stenosis of $79 \%$ and an area stenosis of $96 \%$ (B) A single frame angiogram of the right coronary artery filmed in right anterior oblique projection after directional atherectomy. Minimal luminal diameter increased to $2.27 \mathrm{~mm}$, corresponding to a diameter stensosis of $21 \%$ and an area stenosis of 38\% . (C) Contour analysis of the atherectomy device and inflated support balloon with diameter function shown beneath. Mean diameter of the device together with the inflated balloon is $3.06 \mathrm{~mm}$ and device together with the inflated balloon is $3.06 \mathrm{~mm}$ and
the minimal luminal diameter increased from $0.71 \mathrm{~mm}$ to $2 \cdot 27 \mathrm{~mm}$. 
to identify intima, media, and adventitia. Special attention was paid to the morphological structure of the removed tissue. Three types of lesions were encountered: atherosclerotic plaque, intimal fibrous proliferation, and thrombus. An atherosclerotic plaque was defined as dense fibrotic tissue while intimal hyperplasia was characterised by the proliferation of smooth muscle cells within a loose connective tissue matrix. Thrombus was defined as a laminar structure of fibrin, platelets, and erythrocytes. An organised thrombus was characterised by capillary vessel ingrowth. Specimens obtained from stent patients were stained with monoclonal antibodies specific for desmin, vimentin, and $\alpha$ smooth muscle actin.

\section{Results}

PROCEDURAL AND ANGIOGRAPHIC RESULTS

Sixty two patients underwent 68 attempts at atherectomy. Atherectomy was not possible in four patients for technical reasons. On two occasions the guiding catheter would not fit properly into the coronary ostium and on two occasions the atherectomy device could not pass the stenosis. These patients subsequently underwent conventional coronary angioplasty. Thus 58 patients underwent atherectomy in 64 lesions.

Sufficient atheroma was removed to reduce the angiographic stenosis to $<50 \%$ of the reference diameter in $54(93 \%)$ of 58 patients or in $60(94 \%)$ of 64 stenoses. Additional balloon dilatation was never required and all patients left the catheterisation suite with a residual stenosis of $<50 \%$ of the reference diameter. Figure 2 shows a quantitative angiographic analysis of a successful atherectomy procedure in a right coronary artery. For the lesions successfully treated the mean diameter stenosis decreased from $62(11) \%$ to $22(12) \%$. Three patients underwent a conventional balloon angioplasty of other coronary stenoses after the successful atherectomy procedure.

Atherectomy was regarded as unsuccessful in four patients $(7 \%)$ or in four stenoses $(6 \%)$. All had a residual stenosis of $>50 \%$ of the reference diameter. Three of four patients underwent emergency coronary artery bypass surgery and one had an semi-elective operation 24 hours after atherectomy. This last patient initially underwent a conventional balloon angioplasty of a totally occluded left anterior descending artery which was unsuccessful despite long inflation times and the use of an oversized balloon. To avoid bypass surgery, an initially successful bail-out atherectomy of the totally occluded artery was performed. After 10 minutes, however, the artery became reoccluded with contrast staining in the roof of the artery, though no signs of myocardial ischaemia were present. On the next day the patient underwent a semi-elective coronary bypass grafting operation. One of the three patients who underwent an emergency bypass operation had had a successful atherectomy procedure of the circumflex artery. An attempt to cross the second stenotic lesion in the left descending coronary artery with the device through a considerable bend, however, led to a dissection which resulted in ischaemic electrocardiographic changes and chest pain. Intra-aortic balloon pumping was initiated and the patient was subsequently sent for emergency bypass surgery. In the second patient introduction of the guiding catheter into the right coronary artery was complicated by an obstructive dissection with subsequent chest pain. The patient was referred for emergency surgery. A third patient underwent an emergency bypass operation after atherectomy because immediately after the atherectomy procedure this patient developed chest pain and ischaemic electrocardiographic changes owing to a total occlusion of the treated left
Figure 3 Changes in reference diameter, obstruction diameter, area plaque, and diameter stenosis before and after coronary atherectomy. Reference diameter did not increase significantly, obstruction diameter increased from $1 \cdot 1$ $(0.4) \mathrm{mm}$ to 2.5 (0.5) $\mathrm{mm}$, area plaque decreased from $9 \cdot 1$ (6.3) $\mathrm{mm}^{2}$ to $2 \cdot 6$

(1.8) $\mathrm{mm}^{2}$, and diameter stenosis decreased from 62 (11) \% to $22(15) \%$.
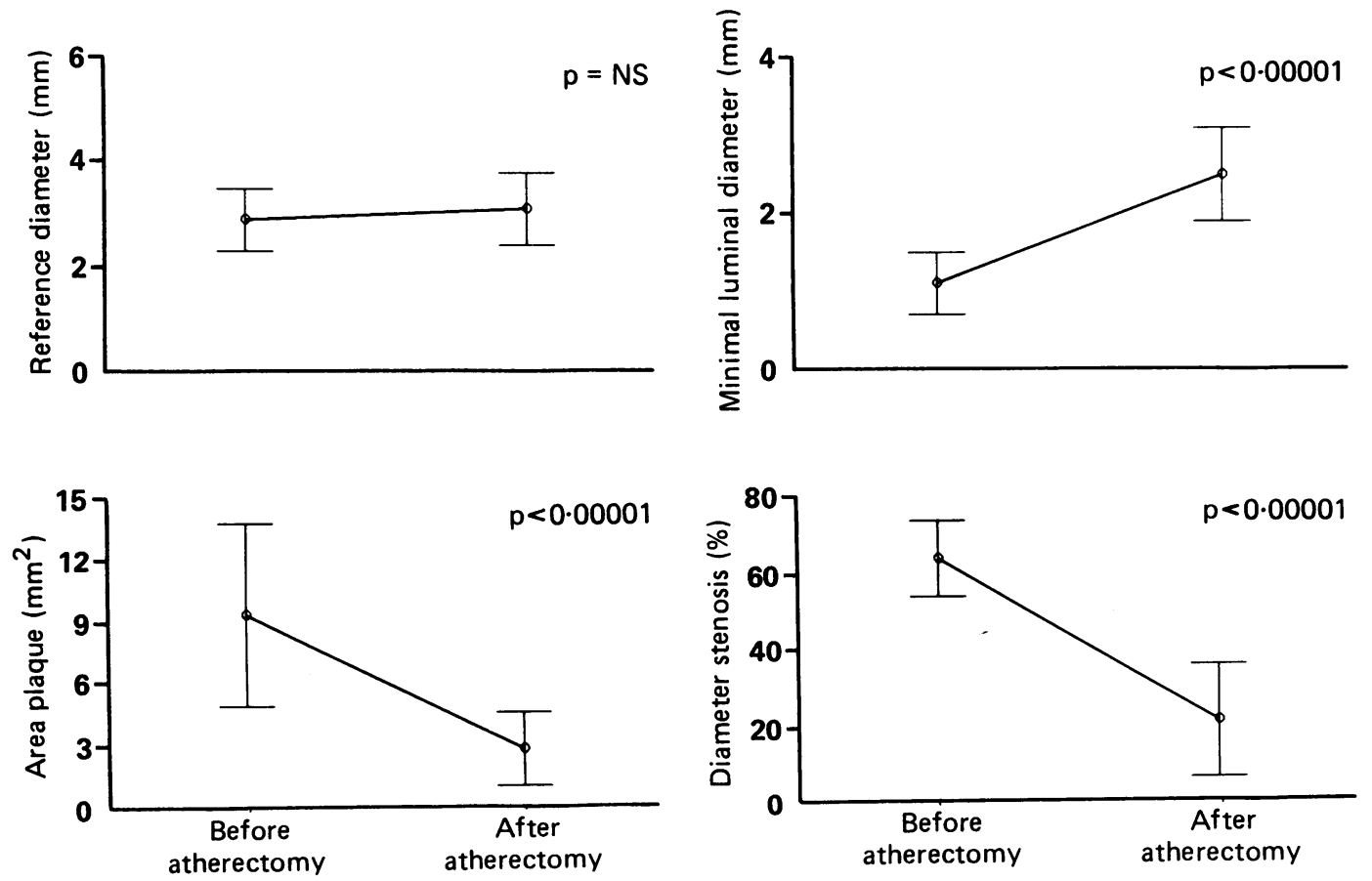
anterior descending coronary artery. Before operation a stent was successfully implanted in a bail-out operation.

\section{QUANTITATIVE CORONARY ANGIOGRAPHY}

The mean (SD) length of the diseased segment was $6.4(2.5) \mathrm{mm}$. The symmetry score showed that 59 of the 64 lesions were eccentric (symmetry index $<1.0$ ). The mean curvature value for all analysed segments was $14.5(7 \cdot 1)$. On average the minimal luminal diameter before atherectomy was $1 \cdot 1(0.4) \mathrm{mm}$. Post-atherectomy it increased to $2.5(0.5 \mathrm{~mm})(\mathrm{p}<0.00001)$ (fig 3). The diameter stenosis decreased from 62 (11) \% to $22(15) \%$ ( $p<0.00001)$, likewise the area stenosis decreased from $84(9) \%$ to 37 $(18) \%(p<0.00001)$. The reference diameter remained unchanged. The atherectomy device itself was also quantitatively analysed on the cinefilms. The mean diameter of the housing at its widest diameter was $2 \cdot 1 \mathrm{~mm}$. Inflation of the support balloon resulted in a diameter increase to $3.4 \mathrm{~mm}(2 \cdot 1-4.3 \mathrm{~mm})$.

\section{IN-HOSPITAL COMPLICATIONS}

Table 2 summarises the complications during the hospital stay. Six of the 54 patients who underwent a successful atherectomy procedure developed in-hospital complications. Two patients sustained a transmural and two a subendocardial myocardial infarction owing to embolisation of plaque material $(n=2)$, side branch occlusion $(n=1)$, or distal occlusion of the treated artery $(n=1)$. None of these patients needed an additional intervention and all of them left hospital without angina. One patient sustained a transient ischaemic attack, but completely recovered within three hours. One patient died of a delayed rupture of the atherectomised vessel three days after a "bailout" atherectomy for an obstructive dissection after balloon dilatation. ${ }^{20}$

In one patient we faced a serious technical problem. This patient underwent an atherectomy of the left anterior descending coronary artery. During the last cutting pass the collecting chamber broke off the housing, migrated to the periphery of the coronary artery, and closed the distal part of the vessel. This caused chest pain and ischaemic electrocardiographic changes. Fortunately we were able to retrieve the collecting chamber by passing a conventional balloon on the wire catheter through the nose and inflating the balloon in the collecting chamber so that the distal part could be pulled back. Thereafter both the pain and electrocardiographic changes disappeared and the patient's recovery was uneventful without signs of a myocardial infarction.

The three patients who were referred for emergency coronary bypass surgery after an unsuccessful atherectomy procedure sustained a perioperative myocardial infarction. All patients had an uncomplicated postoperative clinical course and were discharged without anginal symptoms. The patient who underwent a semi-elective bypass operation had no complications at follow up examination.
Table 2 Complications of atherectomy

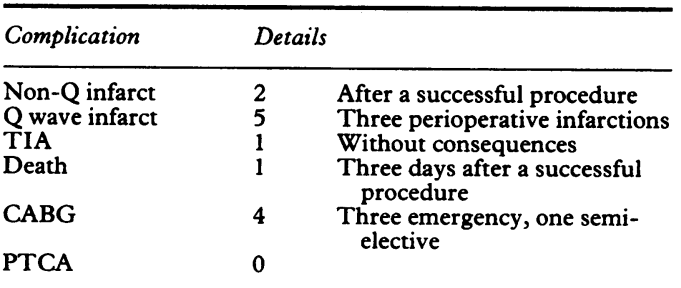

CABG, coronary artery bypass grafting; PTCA, percutaneous transluminal coronary angioplasty; TIA, transient ischaemic

ATHERECTOMY VERSUS ANGIOPLASTY

Matching according to lesion distribution and reference diameter was regarded as adequate because the reference diameter was equal in both groups $(3.0(0.6) \mathrm{mm})$ and the mean difference between the groups was 0.0 $(0 \cdot 2) \mathrm{mm}$. No differences were found before the procedure between the atherectomy and angioplasty groups: minimal luminal diameter $(1 \cdot 1(0.4) \mathrm{mm} v 1 \cdot 1(0.3) \mathrm{mm})$, diameter stenosis $(63(10) \%$ v $63(9) \%)$, area plaque $(9 \cdot 1$ $(6.0) \mathrm{mm}^{2}$ v $\left.8.4(4.6) \mathrm{mm}^{2}\right)$, and symmetry value $(0.5(0.3) v 0.4(0.3))$. The curvature value in the atherectomy group was less than in the angioplasty group $(15.9(7 \cdot 0) v 22.2(13 \cdot 1))$. Directional atherectomy increased the minimal luminal diameter from $1 \cdot 1(0.4) \mathrm{mm}$ to $2 \cdot 7$ $(0.4) \mathrm{mm}$ and angioplasty increased it from $1 \cdot 1$ $(0.3) \mathrm{mm}$ to $1.9(0.4) \mathrm{mm}$. In addition, the diameter stenosis decreased from $63(10) \%$ to $18(8) \%$ after atherectomy and from $63(9) \%$ to $36(11) \%$ after balloon dilatation. Similarly, the plaque area was reduced from $9 \cdot 1(6.0) \mathrm{mm}^{2}$ to $2.4(1.7) \mathrm{mm}^{2}$ after atherectomy and from 8.4 (4.6) $\mathrm{mm}^{2}$ to $5.3(4.2) \mathrm{mm}^{2}$ after angioplasty. So the gain in lumen diameter with atherectomy was greater than that with balloon angioplasty $(1.6 v 0.8 \mathrm{~mm} ; \mathrm{p}<0.0001)$.

\section{HISTOLOGY}

The appearance of the removed specimens was highly variable, ranging from translucent strips of white tissue to yellow tissue with brown areas corresponding to thrombus. Tissue samples of 62 of the 64 lesions were examined

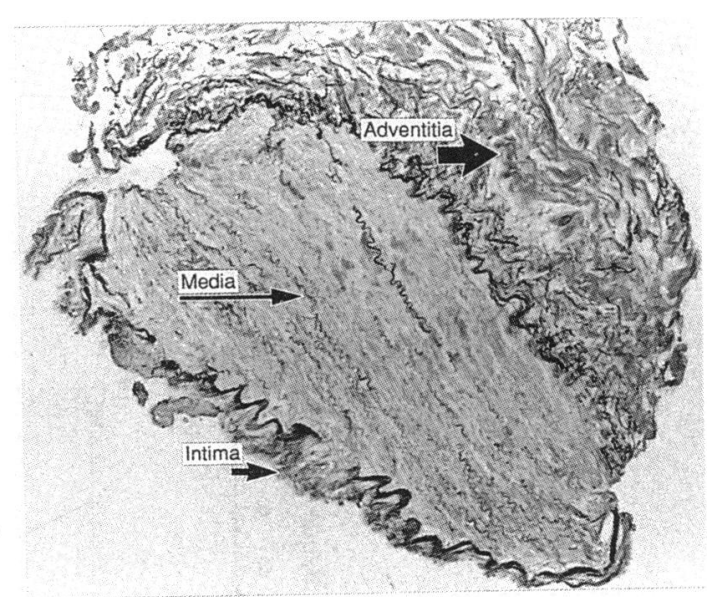

Figure 4 Haematoxylin-azofloxin stained histologica cross-section through a specimen obtained by coronary atherectomy. This specimen contained all three vessel wall components. Internal elastic membrane between intima and media is clearly identified. 
Table 3 Results of 6 month follow up

\begin{tabular}{lr}
\hline Complication & No \\
\hline Angina & 10 \\
Infarction & 1 \\
PTCA/ath/stent & 7 \\
CABG & 2 \\
Death & 0 \\
\hline
\end{tabular}

ath, atherectomy; CABG, coronary artery bypass grafting PTCA, percutaneous transluminal coronary angioplasty.

histologically. No histological specimen was available of the patient who died three days after the atherectomy procedure. The atherectomy specimens were scored for the presence of atheroslerotic plaque; intimal hyperplasia; thrombus; and media and adventitia. Atherosclerotic plaque was found in 35 specimens and intimal hyperplasia was present in 27. Intimal hyperplasia was found in 17 of 19 restenosis cases. Media was found in 16 patients; five of these specimens also contained adventitial tissue (fig 4). In five patients with restenosis after stenting, atherectomy was performed within the stent. Microscopical examination of the excised samples showed intimal hyperplasia with capillary ingrowth suggesting the presence of an organised thrombus. Immunohistochemical staining showed a positive reaction with antibodies for vimentin and alpha smooth muscle cell actin that was consistent with the presence of myofibroblasts.

CLINICAL FOLLOW UP

At one month 50 of the 54 patients who underwent a successful atherectomy were free of angina. One patient with incomplete revascularisation was in New York Heart Association functional class II, one patient suffered a myocardial infarction, one patient underwent a balloon angioplasty for early restenosis, and one patient had coronary bypass grafting eight days after a successful atherectomy procedure. This patient was operated upon because of a suspected pericarditis in the presence of a coronary aneurysm (shown on the coronary angiogram) and possible perforation. At surgery no pericardial fluid was found.

Forty six of the 54 patients who underwent a successful atherectomy procedure completed their six months clinical follow up (table 3 ). Thirty six patients $(80 \%)$ had a persistent successful long term clinical course. Ten patients complained of recurrent angina: two were treated medically, four had a balloon angioplasty for restenosis, one underwent a second atherectomy procedure for restenosis, and one had an atherectomy for a new stenosis, one underwent stent implantation for restenosis, and one patient had a coronary bypass operation because of a restenosis with extensive three vessel disease.

\section{Discussion}

Although balloon angioplasty has excellent short term results with an initial success rate of over $90 \%,{ }^{23}$ a few complications can cause serious problems. Various pre-procedural angiographical risk factors have been identified for acute complications. Among these are lesion length, bend and branch point, ${ }^{4}$ lesion eccentricity, calcification, ${ }^{212}$ and myocardial jeopardy score. $^{23}$

Acute coronary occlusion is the major cause of in-hospital morbidity and mortality. Such an acute coronary occlusion is usually secondary to a coronary dissection. ${ }^{57}$ In experimental preparations dissections have been found most often in areas containing thick and multiple atherosclerotic plaques. ${ }^{24}$ Therefore, it is not surprising that acute occlusion is related to lesion length, which seems to correlate with the amount of atherosclerotic material at the site of balloon inflation.

Because of these observations, conventional coronary angioplasty may not be the ideal nonoperative treatment of large and eccentric plaque in proximal coronary artery disease. Recently, new techniques that remove the atherosclerotic plaque have been introduced for the treatment of obstructed coronary arteries..$^{8-11}$ Directional coronary atherectomy is one such new alternative to conventional angioplasty that is especially used for high risk lesions-that is, a long eccentric stenosis. In this series $92 \%$ had an eccentric score of $<1 \cdot 0$.

\section{COMPARISON OF ATHERECTOMY AND BALLOON}

ANGIOPLASTY

With the advent of various new devices designed to treat coronary stenotic lesions it becomes difficult to define the proper indications. Directional atherectomy is currently used as an alternative to balloon angioplasty for the treatment of proximal large and eccentric plaque. Initial experience showed a high initial success rate with a reasonable complication rate. ${ }^{13-16}$ But we do not know whether atherectomy is better than conventional balloon angioplasty for the treatment of eccentric coronary stenosis. So far there have been no prospective randomised trials to compare atherectomy with balloon angioplasty.

We used quantitative coronary artery analysis to assess the outcome of coronary atherectomy because it is the most objective method available. A computer based automatic edge detection angiographic analysis system such as this allows an accurate morphological description of the lesion that can be used to assess both the immediate and long term results of interventional techniques. When we closely matched stenoses treated by atherectomy with comparable stenoses treated by balloon angioplasty we found that atherectomy increased the minimal luminal diameter more than balloon angioplasty $(1.6 v 0.8 \mathrm{~mm} ; \mathrm{p}<0.0001)$. Although balloon angioplasty can efficiently dilate a lesion when the balloon is fully inflated, part of the luminal diameter increase will be lost due to the recoil phenomenon. ${ }^{12}$ Remodelling by compression (the Dotter effect) accounts for some of the increase in luminal diameter after angioplasty. We do not know the extent of the contribution of the Dotter effect during directional atherectomy. This would require a randomised trial in which the three stages of the atherectomy procedure (crossing the stenosis by the device, subsequent inflation of the support balloon, and the cutting manoeuvre) 
were separately assessed by quantitative angiography. Such a study is precluded by ethical considerations.

Does the removal of atheromatous tissue explain the improvement in the luminal diameter? Rensing et al and others suggested that part of the luminal improvement is due to "facilitated angioplasty". ${ }^{25} 26$ Our study helps to clarify this issue. The intracoronary quantitative assessment of the device size showed a mean diameter of $2.1 \mathrm{~mm}$ increasing to $3.4 \mathrm{~mm}$ after balloon inflation, while the minimal luminal obstruction diameter and reference diameter were $1.1 \mathrm{~mm}$ and $3.0 \mathrm{~mm}$, respectively. The introduction of the atherectomy device itself has a "dottering" effect that is subsequently combined with an angioplasty effect when the support balloon is inflated.

Atherectomy was predominantly performed in long eccentric stenoses located in a proximal coronary artery containing a large atheromatous mass. Our primary angiographic success rate $(87 \%)$, based on intention to treat analysis, is similar to the results reported so far. ${ }^{13-16}$ The treatment of such a lesion is currently a major challenge in interventional cardiology because it is known that the risk of acute complication is high in these lesions. We need a randomised study to establish whether these lesions are more safely and successfully treated by atherectomy than by conventional balloon dilatation.

POTENTIAL RISKS

This new and vigorous technique produces a larger luminal diameter than any other intracoronary interventional technique. ${ }^{25} 27$ Because the depth of the resection and precise spacial orientation of the device are not controlled, it is possible to remove both medial and adventitial tissue. In one study adventitia was identified in $30 \%$ of the resected specimens. ${ }^{28}$ The $26 \%$ incidence of media in our specimens supports these findings.

In one of our patients coronary perforation occurred three days after a bail-out atherectomy. Conventional angioplasty had led to an obstructive dissection which was removed by atherectomy; three days later the patient died of cardiac tamponade. In one patient formation of a coronary aneurysm occurred after the use of a relatively oversized $7 \mathrm{~F}$ atherectomy device. Embolisation of atheromatous material from the plaque to the periphery of the treated vessel occurred in two patients resulting in a non- $Q$ wave infarction. Side branch occlusion was noted once. With the use of an 11 French sheath, major groin complications may occur; however, none of our patients developed a haematoma requiring blood transfusion or vascular surgical repair. These cases underline the risks associated with the aggressiveness of atherectomy. In future the device will undoubtedly be modified to produce smaller, more flexible, and less traumatic systems.

\section{ATHERECTOMY AS A BIOPSY TECHNIOUE}

Recently Johnson et al reported their histological observations on excised peripheral arterial tissue from atherectomy procedures. ${ }^{29}$
They found that $75 \%$ of restenosis showed intimal fibrous proliferation compared with $9 \%$ in primary atherectomy lesions which consisted predominantly of typical atherosclerotic plaque.$^{29}$ Our results are consistent with theirs: $89 \%$ of restenoses showed intimal hyperplasia compared with $24 \%$ of primary stenoses.

In our study atherectomy was performed within a stent on five occasions. The tissue excised resembled that of other restenosis specimens. Microscopy showed intimal hyperplasia and capillary ingrowth. Immunohistochemical staining showed that most of these cells were smooth muscle cells. We and others are currently investigating the behaviour of smooth muscle cells in culture from atherectomy material. ${ }^{20} 30$ Thus atherectomy can be used to obtain material to throw light on the development of restenosis or to monitor pharmacological treatments.

Directional coronary atherectomy is an effective non-operative treatment of coronary artery lesions. It is particularly effective in removing atheromatous tissue specimens from eccentric lesions which are not particularly amenable to conventional balloon angioplasty. Quantitative analysis of the immediate results after coronary atherectomy shows a greater gain in minimal luminal diameter than with balloon angioplasty. Using quantitative analysis we found evidence that a facilitated angioplasty effect partly accounts for the luminal improvement. Because the depth and site of the resection is not controlled, atherectomy can lead to serious complications. Atherectomy is a method of obtaining human (re)stenosis tissue which can be used to study the causes of restenosis. Despite the encouraging short term results, however, we need further studies of the ultimate indications and long term follow up.

BHS is a research fellow of the Canadian Heart Foundation.

1 Gruentzig AR. Transluminal dilatation of coronary artery stenosis. Lancet 1978;1:263.

2 Dorros G, Cowley MJ, Simpson J, et al. Percutaneous transluminal coronary angioplasty: report of complicaions of the National Heart, Blood and Lung Institute PTCA registry. Circulation 1983;67:723-30.

3 Faxon DP, Kelsey SF, Ryan TJ, McCabe CH, Detre K. Determinants of successful percutaneous transluminal Determinants of successful percutaneous transluminal Am J Cardiol 1984;108:1019-23.

4 Ellis SG, Roubin GS, King SB, et al. Angiographic and clinical predictors of acute closure after native vessel clinical predictors of acute closure after native

5 de Feyter PJ, van den Brand M, Laarman GJ, van Domburg R, Serruys PW, Suryapranata H. Acute coronary occlusion during and after percutaneous transluminal coronary angioplasty: frequency, prediction, clinical course,

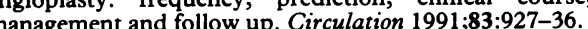

6 Block P, Myler R, Stertzer S, Fallon J. Morphology after transluminal angioplasty in human beings. $N$ Engl J Med 1981;305:382-4.

Suryapranata H, de Feyter PJ, Serruys PW. Coronary angioplasty in patients with unstable angina pectoris: is there a role for thrombolysis? J Am Coll Cardiol 1988, 12:69A-77A.

8 Waller BF. "Crackers, breakers, stretchers, drillers, scrapers, burner, welters and melters" - the future treatment of atherosclerotic coronary artery disease? A clinical morphologic assessment. J Am Coll Cardiol 1989;13: 969-87.

9 Simpson JB, Selmon MR, Robertson GC, et al. Transluminal atherectomy for occlusive peripheral vascular disease. Am J Cardiol 1988;61:96G-101G.

10 Fourier JL, Bertrand NE, Auth DC, Lablanche JM, Gommeaux A, Brunetaud JM. Percutaneous coronary Gommeaux A, Brunetaud JM. Percutaneous coronary rotational angioplasty in humans:

11 Stack RS, Quigley PJ, Sketch MH Jr, et al. Treatment of 
coronary artery disease with the transluminal extractionendarterectomy catheter: initial results of a multicenter study [abstract]. Circulation 1989;80(suppl II):II-583.

12 Rensing BJ, Hermans W, Beatt KJ, et al. Quantitative angiographic assessment of elastic recoil after percutaneous transluminal coronary angioplasty. $\mathrm{Am} \mathrm{J}$ Cardiol 1990;66:1039-44.

13 Vlietstra RE, Abbotsmith CW, Douglas JS, et al. Complications with directional coronary atherectomy. Experience at eight centers [abstract]. Circulation 1989;80 (suppl

14 Safian RD, Gelbfish JS, Erny RE, Schnitt DA, Baim D. Coronary atherectomy: clinical, angiographic, and histologic findings and observations regarding potential mechanism. Circulation 1990;82:69-79.

15 Robertson C, Hinohara T, Selmon M, Johnson DA, Simpson J. Directional coronary atherectomy. In: Topo EJ, ed. Textbook of interventional cardiology. Philadelphia:
Saunders, 1990:563-79.

16 Garrat KN, Holmes DR, Bell MR, et al. Restenosis after directional coronary atherectomy: differences between primary atheromatous and restenosis lesions and influence of subintimal tissue resection. J Am Coll Cardiol 1990; 16:1655-71.

17 Serruys PW, Reiber JHC, Wijns W, et al. Assessment of percutaneous transluminal coronary angioplasty by quantitative coronary angiography: diameter versus densitometric area measurements. Am J Cardiol 1984;54: 482-8.

18 Reiber JHC, Serruys PW, Kooyman CJ, et al. Assessment of short-, medium- and long-term variations in arterial dimensions from computer-assisted quantitation of coronary cineangiograms. Circulation 1985;71:280-8.

19 Bland JM, Altman DG. Statistical methods for assessing agreement between two methods of clinical measurements. Lancet 1986;i:307-10.

20 Strauss BH, Verkerk A, van Suylen RJ, et al. Smooth muscle cell culture from human coronary lesions [abstract]. Circulation 1990;82(suppl III): 496.
21 Fisch C, deSanctis RW, Dodge HT, Reeves J, Weinberg SL. Guidelines for percutaneous transluminal coronary angioplasty, a report of the ACC/AHA task force on assessment of diagnostic or therapeutic cardiovascular procedures. Circulation 1988;78:486-502.

22 Bredlau CE, Roubin G, Leimgruber P, Douglas J, King S, Gruentzig A. In-hospital morbidity and mortality in patients undergoing elective coronary angioplasty.

23 Ellis SG, Roubin GS, King SB, et al. In-hospital mortality after acute closure after coronary angioplasty: analysis of risk factors from 8207 procedures. J Am Coll Cardiol 1988; 11:211-6.

24 Zollikofer C, Chain J, Salomonowitz E, et al. Percutaneous transluminal angioplasty of the aorta. Radiology 1984;151: 355-60.

25 Rensing BJWM, Serruys PW, Laarman GJ, et al. Directional coronary atherectomy, first Dutch experience with a new percutaneous revascularisation technique [in Dutch]. Ned Tijdschr Geneeskd 1990;134:962-7.

26 Erny RE, Gelbfish JS, Safian RD, Diver DJ, Baim DS. Does tissue removal explain all atherectomy improvement? [abstract] Circulation 1989;80(suppl II):582.

27 Serruys PW, Strauss BH, van Beusekom HM, van den Giessen WI. Stenting of coronary arteries. Has a modern Pandora's Box been opened? J Am Coll Cardiol 1991; 17:143B-54B.

28 Garratt KN, Kaufmann UP, Edwards WD, Vlietstra RE, Holmes DR Jr. Safety of percutanous coronary atherectomy with deep arterial resection. Am J Cardiol 1989;64: $538-40$.

29 Johnson DE, Hinohara T, Selmon MR, Braden LJ, Simpson JB. Primary peripheral arterial stenosis and restenosis excised by transluminal atherectomy: a histopathological study. J Am Coll Cardiol 1990;15:419-25.

30 Dartch PC, Bauriedel G, Sckinko I, et al. Cell constitution and characteristics of human atherosclerotic plaques selectively removed by percutaneous atherectomy. Atherosclerosis 1989;80:149-57. 